\title{
Circulating microRNAs predict biochemical recurrence in prostate cancer patients
}

\author{
L A Selth ${ }^{*}, 1$, S L Townley ${ }^{1}$, A G Bert ${ }^{2}$, P D Stricker ${ }^{3}$, P D Sutherland ${ }^{4}$, L G Horvath ${ }^{5,6}$, G J Goodall ${ }^{2,7}$, \\ L M Butler ${ }^{1}$ and W D Tilley ${ }^{1}$ on behalf of the Australian Prostate Cancer BioResource
}

${ }^{1}$ Dame Roma Mitchell Cancer Research Laboratories, Adelaide Prostate Cancer Research Centre, University of Adelaide and Hanson Institute, PO Box 14, Rundle Mall, Adelaide, South Australia 5000, Australia; ${ }^{2}$ Division of Human Immunology, Centre for Cancer Biology, SA Pathology, Adelaide, South Australia 5000, Australia; ${ }^{3}$ Department of Urology, St Vincent's Clinic, Darlinghurst, New South Wales 2010, Australia; ${ }^{4}$ Urology Unit, Surgical Specialties Service, Royal Adelaide Hospital, Adelaide, South Australia 5000, Australia; ${ }^{5}$ Department of Medical Oncology, Sydney Cancer Centre, Royal Prince Alfred Hospital, Missenden Road, Camperdown, New South Wales 2050, Australia; ${ }^{6}$ Cancer Research Program, The Kinghorn Cancer Centre/Garvan Institute of Medical Research, Darlinghurst, New South Wales 2010, Australia and ${ }^{7}$ Discipline of Medicine, The University of Adelaide, Adelaide, South Australia 5005, Australia

Background: Circulating microRNAs (miRNAs) are emerging as promising biomarkers for prostate cancer. Here, we investigated the potential of these molecules to assist in prognosis and treatment decision-making.

Methods: MicroRNAs in the serum of patients who had experienced rapid biochemical recurrence (BCR) $(n=8)$ or no recurrence $(n=8)$ following radical prostatectomy (RP) were profiled using high-throughput qRT-PCR. Recurrence-associated miRNAs were subsequently quantitated by qRT-PCR in a validation cohort comprised of 70 patients with Gleason 7 cancers treated by RP, 31 of whom had undergone disease progression following surgery. The expression of recurrence-associated miRNAs was also examined in tumour tissue cohorts.

Results: Three miRNAs - miR-141, miR-146b-3p and miR-194 - were elevated in patients who subsequently experienced BCR in the screening study. MiR-146b-3p and miR-194 were also associated with disease progression in the validation cohort, as determined by log-rank tests and Cox proportional hazards regression. Multivariate analysis revealed that miR-146b-3p possessed prognostic information beyond standard clinicopathological parameters. Analysis of tissue cohorts revealed that miR-194 was robustly expressed in the prostate, elevated in metastases, and its expression in primary tumours was associated with a poor prognosis.

Conclusion: Our study suggests that circulating miRNAs, measured at the time of RP, could be combined with current prognostic tools to predict future disease progression in men with intermediate risk prostate cancers.

Prostate cancer is a major cause of cancer-related death (Jemal et al, 2011). However, disease course is highly variable and difficult to predict: a significant proportion of cases are indolent and do not require curative treatment, whereas others are characterised by high metastatic potential and require aggressive, early clinical intervention. Unfortunately, current clinicopathological models, which incorporate parameters such as Gleason score, tumour stage and serum prostate-specific antigen (PSA) concentration, are unable to accurately differentiate between indolent and lifethreatening cancers at the time of diagnosis. Subsequently, there is considerable overtreatment of indolent disease, accompanied by high morbidity. The issue of overtreatment has been further compounded by PSA testing (Andriole et al, 2009; Schroder et al, 2009; Chou et al, 2011). More accurate prognostic 
tools would have a major impact on the clinical management of prostate cancer.

MicroRNAs (miRNAs) are small non-protein-coding RNA molecules that regulate gene expression by binding to complementary sequences in target mRNAs and mediating translational repression and/or mRNA degradation. A recent estimate suggests that $\sim 60 \%$ of all protein-coding genes are directly targeted by miRNAs (Friedman et al, 2009). It is therefore unsurprising that miRNAs have demonstrated functions in a diverse array of processes, including development, cell behaviour, stress responses and survival (Bushati and Cohen, 2007).

In addition to their roles in normal physiology, miRNAs are frequently dysregulated in cancer (Croce, 2009). This paradigm suggests that miRNAs could be clinically useful cancer biomarkers, a concept recently validated by the launch of miRNA-based diagnostic tests for thyroid and pancreatic cancer by Asuragen. The potential of miRNAs for biomarker applications was further reinforced by recent research showing that cancer-specific miRNAs are detectable in cell-free blood fluids such as serum and plasma (Lawrie et al, 2008; Mitchell et al, 2008). Since those seminal studies, circulating miRNAs have emerged as promising biomarkers for various malignancies (Weiland et al, 2012). In relation to prostate cancer, most studies to date have focused on identifying circulating miRNAs that can assist in diagnosis or the stratification of metastatic from localised disease (Kelly et al, 2012; Selth et al, 2012). While a subset of these molecules have been linked to prognostic clinical variables (Brase et al, 2011; Selth et al, 2011), the utility of circulating miRNAs to predict disease course at the time of diagnosis remains inconclusive. In this study, we report on the ability of circulating miRNAs to predict biochemical recurrence (BCR) in men with localised prostate cancer treated by radical prostatectomy $(\mathrm{RP})$.

\section{MATERIALS AND METHODS}

Human serum samples. The Australian Prostate Cancer BioResource (APCB) collected biological samples and clinical data from men undergoing RP at the Royal Adelaide Hospital (RAH) and St Vincent's Hospital (SVH), Sydney. All men gave written consent for sample and ongoing data collection, and practices and procedures were approved by the RAH and SVH Human Research Ethics Committees. Blood was collected according to the APCB's standard operating procedures, which have been reviewed within Australia and by the International Society of Biological and Environmental Repositories. Samples were collected in 8-ml Serum Separator Gel Vacuette tubes (Greiner BioOne, Frickenhausen, Germany; catalogue number 455078), allowed to clot for $\sim 30 \mathrm{~min}$ at room temperature and centrifuged at room temperature for $10 \mathrm{~min}$ at $2500 \mathrm{~g}$. Serum was aliquoted into Nunc cryovials (ThermoFisher Scientific, San Jose, CA, USA), snap frozen in liquid nitrogen and stored at $-80^{\circ} \mathrm{C}$. Patients were followed postoperatively by their surgeons on a monthly basis until satisfactory urinary continence was obtained and then at 3-month intervals until the end of the first year, at 6-monthly intervals to 5 years and yearly thereafter. Relapse was defined by the following criteria: biochemical disease progression with a serum PSA concentration of $0.2 \mathrm{ng} \mathrm{ml}^{-1}$ increasing over a 3 -month period.

RNA extraction. Total RNA was extracted from serum essentially as described previously (Selth et al, 2011), with some minor modifications. Before extraction, serum was centrifuged at $3000 \mathrm{~g}$ for $5 \mathrm{~min}$ at $4{ }^{\circ} \mathrm{C}$ and transferred to a new $1.5 \mathrm{ml}$ tube. A serum to Qiazol ratio of 1:5 was used to denature the samples. For the samples profiled by high-throughput qRT-PCR, miRNAs were extracted from $500 \mu \mathrm{l}$ serum spiked with 25 fmol synthetic cel-miR-39 (Integrated DNA Technologies, Coralville, IA, USA) and eluted in
$35 \mu \mathrm{l}$ RNase-free water. For the validation samples, miRNAs were extracted from $200 \mu \mathrm{l}$ serum spiked with 25 fmol synthetic cel-miR-39 and eluted in $100 \mu \mathrm{l}$ RNase-free water. Additionally, $1 \mu \mathrm{g}$ of yeast transfer RNA (Roche, Mannheim, Germany) was added to the smaller validation serum samples as a carrier.

TaqMan Low-Density arrays. Serum samples from two disparate patient groups - men who experienced rapid BCR following RP and men who were progression free at the time of last follow-up were profiled using TaqMan Low-Density Array (TLDA) Human MicroRNA A + B Cards Set v3.0 (Applied Biosystems, Foster City, CA, USA), as per the manufacturer's instructions. We used $3 \mu \mathrm{l}$ of serum miRNA as input for the Megaplex reverse transcription (RT) reactions. After RT and pre-amplification, quantitative PCR was carried out on an Applied Biosystems 7900HT. Cycle threshold values were calculated using SDS 2.4 software (Applied Biosystems) with manual baseline (3-15) and threshold (0.2) settings.

Undetected miRNAs (average quantification cycle value $(\mathrm{Cq})>35$ in either the BCR or no BCR groups) were removed from the analysis. Normalisation of the data was as follows: (1) the A plates and $\mathrm{B}$ plates were normalised to each other using the $\mathrm{Cq}$ values for U6 snRNA, which is amplified on both plates; (2) all data were then scaled to the spiked-in cel-miR-39 to correct for differences in extraction efficiency, (3) finally, the mean Cq value of all miRNAs with a $\mathrm{Cq}$ value of $<30$ for each array was determined and used to normalise the arrays. This global normalisation strategy improves upon methods based on internal reference genes (Mestdagh et al, 2009; Deo et al, 2011). Raw and normalised data have been deposited in Gene Expression Omnibus (accession number GSE47125).

Quantitative RT-PCR analysis of circulating miRNAs in validation cohort. To validate miRNAs identified by TLDA profiling, TaqMan Human miRNA assays (Applied Biosystems) were used to measure the levels of miR-141, miR-146b-3p, miR-194 and $m i R-375$ (assay numbers 000463, 002361, 000493 and 000564, respectively) in 70 independent patient serum samples enriched for men who had experienced recurrence post-RP. Spiked-in cel-miR39 (assay number 000200) was used for normalisation purposes. TaqMan MicroRNA Reverse Transcription Kits (Applied Biosystems) were used to synthesise cDNA from $4 \mu \mathrm{l}$ of total serum RNA (in $10 \mu \mathrm{l}$ reactions). The miRNA-specific stem-loop primers for $m i R-141, m i R-146 b-3 p, m i R-194, m i R-375$ and $c e l-m i R-$ 39 were pooled, dried down in a speed-vac, resuspended in RNasefree water and used at a final concentration of $0.3125 \times$, as described in the Applied Biosystems Protocol for Creating Custom RT and Preamplification Pools using TaqMan MicroRNA Assays. One microlitre of the RT product was used in $10 \mu \mathrm{l}$ preamplification reactions containing $0.5 \times$ concentration of $m i R$ 141, $m i R-146 b-3 p$, $m i R-194$ and miR-375 TaqMan MicroRNA assays, as described previously (Selth et al, 2011). The pre-amplification product was then diluted 10-fold in RNase-free water and $2 \mu \mathrm{l}$ used in real-time PCRs containing $1 \times$ concentrations of individual TaqMan MicroRNA assays and $5 \mu \mathrm{l}$ of TaqMan Universal Master Mix, No AmpErase UNG (Applied Biosystems). Cel-miR-39 was quantified by adding $2 \mu \mathrm{l}$ of 10 -fold diluted cDNA (not pre-amplified) in realtime PCRs as described above. Cq values of endogenous miRNAs were normalised to $\mathrm{cel}-\mathrm{miR}-39 \mathrm{Cq}$ values, which ranged from 19.60 to 22.45 (mean 20.73, standard deviation 0.59). In 10 samples, $m i R-146 b-3 p$ was not detected $(\mathrm{Cq}>40)$; for statistical analyses, the $\mathrm{Cq}$ values for these samples were set to the maximum Cq across all samples (Madhavan et al, 2012).

The efficiency and specificity of the assays were confirmed by using synthetic oligonucleotides (Sigma-Aldrich, St Louis, MO, USA) corresponding to mature miRNAs $m i R-141, m i R-146 b-3 p$, $m i R-194, m i R-375$ and cel-miR-39 (sequences obtained from miRBase, release 19). Single oligonucleotide (1 fmol) or an oligonucleotide pool ( $1 \mathrm{fmol}$ of each) was added to single plex 
(i.e., containing single miRNA stem-loop RT primers) or multiplexed (i.e., containing all five miRNA stem-loop RT primers) RT reactions. Reverse transcription products were diluted over four orders of magnitude; the serial dilutions were used in qPCRs containing single Taqman assays to generate standard curves and to determine efficiency values for each assay. Two microlitres of each RT product (1:10000 diluted) was also used as template in either single plex or multiplexed pre-amplification reactions. Preamplified cDNA was diluted over four orders of magnitude and used to generate standard curves and to define qPCR efficiency. Finally, assay specificity was assessed by determining the relative detection of the assay-specific synthetic miRNA $v s$ the four nonspecific synthetic miRNAs in qPCRs following multiplexed $\mathrm{RT} /$ pre-amplification. Cross-reactivity values were calculated based on the Cq difference between assay-specific and non-specific synthetic miRNAs and expressed as percent relative detection.

Analysis of circulating miRNAs in human tumour samples. Serum miRNA markers of prostate cancer recurrence were analysed in two tumour data sets (Taylor et al, 2010; MartensUzunova et al, 2011). The Memorial Sloan-Kettering Cancer Center data set contains miRNA expression data from 99 primary prostate cancers, 28 non-malignant tissues and 14 metastases. The Erasmus Medical Center data set contains miRNA expression data from 50 primary tumours obtained by RP, 22 primary tumours obtained by Transurethral Resection of the Prostate (TURP), 12 lymph-node metastases and 15 normal prostate tissues. Both tissue cohorts were profiled using Agilent microRNA V2 arrays. Raw data were downloaded from GEO (accession number GSE21036) and ArrayExpress (accession number E-TABM-794) and processed using AgiMicroRNA (Lopez-Romero, 2011). Clinical data for the Erasmus Medical Center cohort were kindly provided by Drs E Martens-Uzunova and G Jenster.

Statistical analyses. Biochemical recurrence-free survival was measured from the date of RP to relapse or the date of last follow-up. Differences in serum miRNA levels between the BCR and progression-free groups, as defined by TLDA profiling, were assessed using $t$ tests. The association between serum miRNA levels and BCR in the validation cohort was assessed using Kaplan-Meier survival curves and univariate and multivariate Cox proportional hazards regression. The capacity of serum miRNAs to distinguish between men who experienced recurrence and men who remained disease free was evaluated by ROC curve analysis. Predicted values from logistic regression models were used to generate ROC curves from a combination of variables (i.e., serum miRNAs plus clinical variables). Kruskal-Wallis one-way ANOVA tests were employed to compare miRNA levels among normal prostate tissue, primary tumours and metastatic samples. All statistical analyses were done using GraphPad Prism (version 5; GraphPad Software, San Diego, CA, USA) and MedCalc (version 12; MedCalc Software, Mariakerke, Belgium).

\section{RESULTS}

Circulating miRNAs associated with BCR following RP. Serum samples from 16 patients (Table 1) representing two disparate groups - men who experienced rapid BCR following RP and men with a mean of 53.4 months follow-up post-RP but no evidence of BCR - were profiled using TLDAs. The two groups were otherwise closely matched in terms of clinicopathological parameters such as Gleason score, primary Gleason grade and staging to increase the likelihood of identifying miRNAs that may complement existing prognostic tools. All samples were collected from patients treated at RAH, South Australia. One sample from the BCR group was disregarded following TLDA profiling because the clinical followup data could not be verified.

\begin{tabular}{|c|c|c|c|c|}
\hline Variable & $\begin{array}{c}\text { Total } \\
(n=16)\end{array}$ & $\begin{array}{c}\text { BCR } \\
(n=8)\end{array}$ & $\begin{array}{c}\text { No BCR } \\
(n=8)\end{array}$ & $\boldsymbol{P}$-value ${ }^{a}$ \\
\hline Age, mean \pm s.e.m. (years) & $66.1 \pm 1.1$ & $65.8 \pm 1.4$ & $66.4 \pm 1.8$ & 0.857 \\
\hline $\begin{array}{l}\text { Time to } B C R \text {, mean } \pm \text { s.e.m. } \\
\text { (months) }\end{array}$ & - & $18.9 \pm 4.4$ & - & - \\
\hline $\begin{array}{l}\text { Follow-up, mean } \pm \text { s.e.m. } \\
\text { (months) }\end{array}$ & $54.4 \pm 2.8$ & $55.4 \pm 5.7$ & $53.4 \pm 2.4$ & 0.687 \\
\hline Pre-operative PSA $\left(\mathrm{ng} \mathrm{ml}^{-1}\right)$ & & & & 0.282 \\
\hline$<10$ & 11 & 4 & 7 & \\
\hline$\geqslant 10$ & 5 & 4 & 1 & \\
\hline Primary Gleason grade & & & & 0.467 \\
\hline 3 & 7 & 3 & 4 & \\
\hline 4 & 8 & 5 & 3 & \\
\hline 5 & 1 & 0 & 1 & \\
\hline Gleason score & & & & 1.000 \\
\hline 7 & 12 & 6 & 6 & \\
\hline 8 & 0 & 0 & 0 & \\
\hline 9 & 4 & 2 & 2 & \\
\hline Pathologic stage & & & & 1.000 \\
\hline pT2 & 6 & 3 & 3 & \\
\hline pT3 & 10 & 5 & 5 & \\
\hline
\end{tabular}

After data filtering and normalisation (see Materials and methods), 217 miRNAs were detectable in circulation (Figure 1A). Of these, only $m i R-141, m i R-146 b-3 p$ and $m i R-194$ were differentially expressed between the BCR and no BCR groups $(P<0.05$, no adjustment for multiple testing) (Figure 1B). MiR-141 has been identified as a marker of high-risk and metastatic prostate cancer in previous studies (Mitchell et al, 2008; Brase et al, 2011; Selth et al, 2011; Bryant et al, 2012), suggesting that the TLDA data were robust and our experimental approach was well founded. Other miRNAs previously associated with high-risk and metastatic disease, including miR-375 and miR-200b (Brase et al, 2011; Selth et al, 2011; Bryant et al, 2012), were elevated in men who relapsed but the differences were not statistically significant (Figure 1C).

Recent reports suggest that peripheral blood cells can be a major source of circulating miRNAs (Pritchard et al, 2012). In the absence of blood cell counts or haemoglobin concentrations for our samples, we investigated the levels of miRNAs known to be highly expressed in white (WBC) and red (RBC) blood cells: $m i R-150$ and $m i R-223$ are markers of lymphoid and myeloid WBCs, respectively (Pritchard et al, 2012), while both $m i R-16$ and $m i R-451$ are present at high concentrations in RBCs and can be used to assess haemolysis during serum preparation (Kirschner et al, 2011). The Cq values for these miRNAs are shown in Figure 2A. The expression level and variation in range of $\mathrm{Cq}$ values for the individual miRNAs $(m i R-150,2.4 ; m i R-223,2.6$; $m i R-16,3.2$; $m i R-451,4.4)$ was comparable to that observed in previous studies (Kirschner et al, 2011; Pritchard et al, 2012), suggesting that the levels of miRNAs determined by TLDA qRT-PCR were unlikely to be significantly impacted by contaminating cellular miRNAs. Furthermore, none of the cellular miRNAs were differentially expressed between the BCR and no BCR groups (Figure $2 \mathrm{~B}$ ).

Circulating miR-146b-3p and miR-194 are predictive of disease recurrence following RP. To validate the findings from the screening study, we collected a larger, independent set of patient 


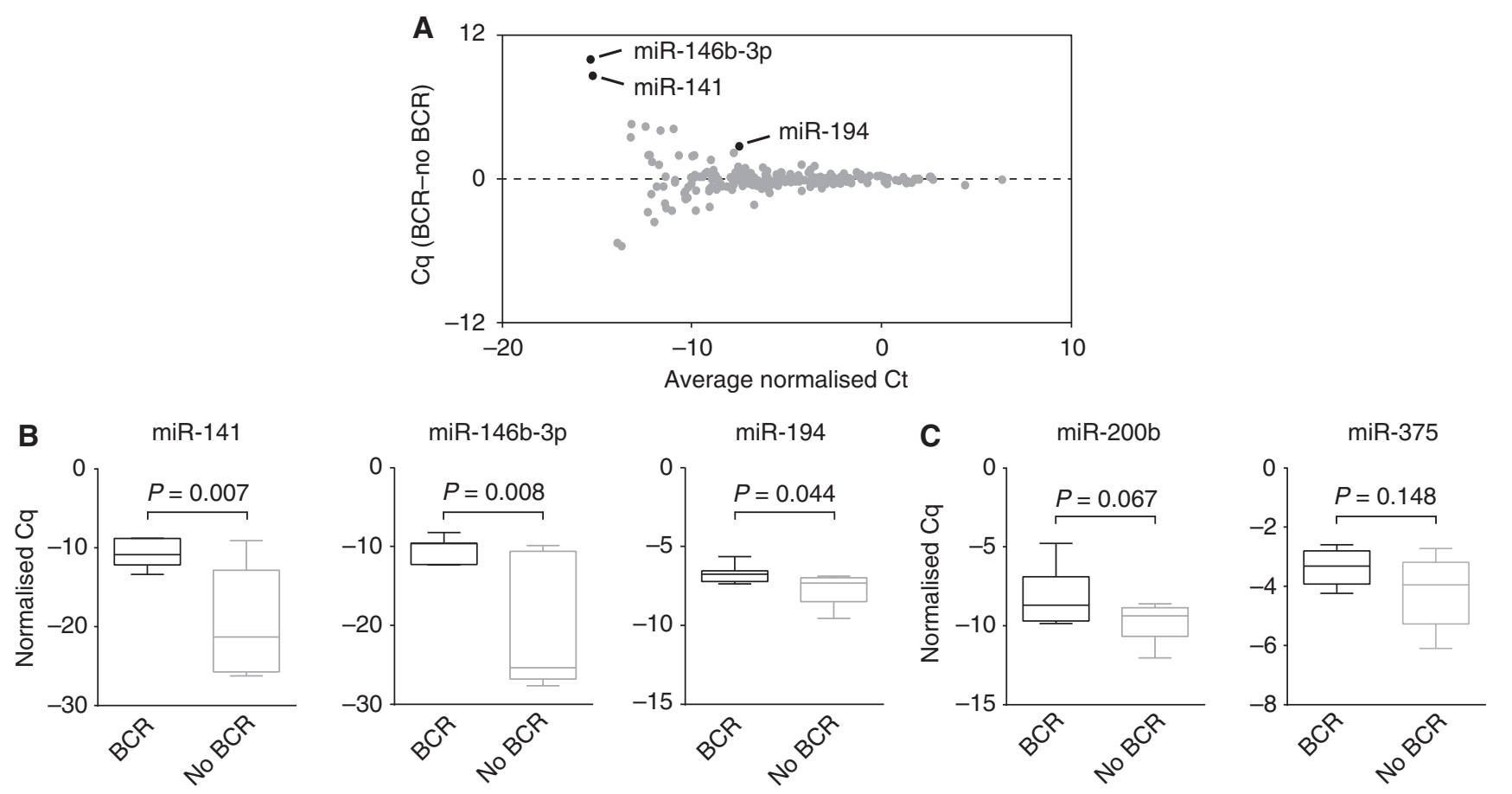

Figure 1. Circulating miRNA markers of biochemical recurrence (BCR). (A) Bland-Altman mean-difference plot of 217 circulating miRNAs detected in a screening cohort of prostate cancer patients. MiRNAs found to be significantly differentially expressed between the BCR ( $n=8$ ) and no BCR $(n=8)$ groups are shown in black. (B) Relative levels of miR-141, miR-146b-3p and miR-194 in the serum of men who experienced $B C R$ and men who did not. Statistically significant differences were assessed using a t-test; $P$-values are shown. The lines within boxes represent the median, the horizontal borders of each box represent the 25th and 75th percentile, and the limits of the vertical lines represent the maximum and minimum Cq. (C) Relative levels of miR-200b and miR-375 in the serum of men who experienced BCR and men who did not, graphed as described in (B).
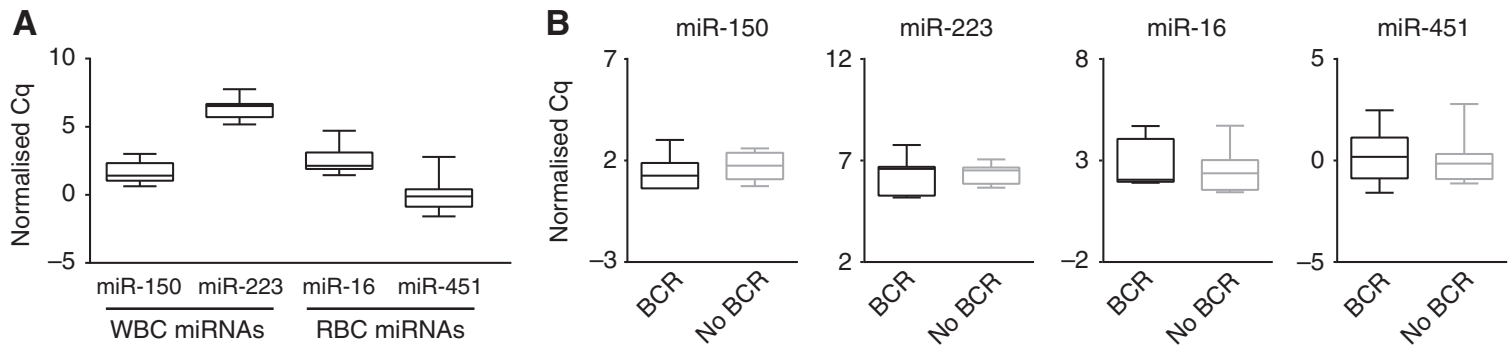

Figure 2. Variation in serum levels of miRNAs expressed at high levels in blood cells. (A) Levels of miR-150 and miR-223 (markers of white blood cells (WBC) and miR-16 and miR-451 (markers of red blood cells (RBC)) in the serum samples used in the screening study. (B) Relative levels of blood cell miRNAs in the serum of men who experienced biochemical recurrence $(B C R ; n=8)$ and men who did not ( $n=8)$. None of the miRNAs were significantly different between the two groups. The lines within boxes represent the median, the horizontal borders of each box represent the 25th and 75th percentile, and the limits of the vertical lines represent the maximum and minimum Cq.

samples from a different site (SVH, New South Wales) to those analysed in the screening study. This validation cohort was comprised of 70 patients and enriched for men who had experienced early BCR following the RP $(n=31$; Table 2$)$. For men who progressed, the median time from RP to recurrence was 24.7 months. All of the cancers had a Gleason score of $7(3+4$ or $4+3)$; as such, the patients represent an intermediate risk group that would benefit from additional markers of disease behaviour (D'Amico et al, 1998). The three miRNAs found to be significantly elevated in patients who subsequently relapsed in the screening study ( $m i R-141, m i R-146 b-3 p$ and $m i R-194)$ were quantitated in serum samples from these patients using qRT-PCR. We also measured $m i R-375$, since it has been previously correlated with adverse risk factors and it was elevated in the BCR group, albeit non-significantly, in our screening study. Levels of the candidate
BCR-associated miRNAs were normalised to spiked-in cel-miR-39 only, since there is no consensus on suitable endogenous small RNAs in circulation for such a purpose (Kroh et al, 2010).

Before quantitation of circulating miRNAs in the validation cohort, we assessed whether multiplexing the RT and preamplification reactions affected the efficiency and/or specificity of the miR-141, miR-146b-3p, miR-194, miR-375 and cel-miR-39 assays. All of the assays performed similarly when used in combination (multiplexed) or individually (Figure 3A). Moreover, qPCR efficiency values of the assays following multiplexed $\mathrm{RT} /$ pre-amplification ranged from $93.8 \%$ to $104.1 \%$, within the commonly employed functional cutoff of $90-110 \%$ (Figure $3 \mathrm{~A}$ ). To evaluate the specificity of the assays, we utilised synthetic mature miRNA molecules as templates in multiplexed RT/pre-amplification reactions followed by $\mathrm{qPCR}$ with individual assays. Only the 


\begin{tabular}{|c|c|c|c|c|}
\hline Variable & $\begin{array}{c}\text { Total } \\
(n=70)\end{array}$ & $\begin{array}{c}\text { BCR } \\
(n=31)\end{array}$ & $\begin{array}{l}\text { No BCR } \\
(n=39)\end{array}$ & $\boldsymbol{P}$-value \\
\hline Age, mean \pm s.e.m. (years) & $62.2 \pm 0.8$ & $62.6 \pm 1.1$ & $61.9 \pm 1.1$ & 0.648 \\
\hline $\begin{array}{l}\text { Follow-up, mean } \pm \text { s.e.m. } \\
\text { (months) }\end{array}$ & $64.2 \pm 1.4$ & $65.1 \pm 2.0$ & $63.4 \pm 2.0$ & 0.872 \\
\hline Pre-operative PSA ( $\mathrm{g} \mathrm{ml}^{-1}$ ) & & & & 0.091 \\
\hline$<10$ & 53 & 20 & 33 & \\
\hline$\geqslant 10$ & 17 & 11 & 6 & \\
\hline Gleason score & & & & 0.053 \\
\hline $3+4$ & 37 & 12 & 25 & \\
\hline $4+3$ & 33 & 19 & 14 & \\
\hline Pathologic stage & & & & 0.114 \\
\hline pT2 & 33 & 11 & 22 & \\
\hline pT3 & 36 & 19 & 17 & \\
\hline pT4 & 1 & 1 & 0 & \\
\hline Surgical margins & & & & 0.275 \\
\hline RO & 51 & 20 & 31 & \\
\hline R1 & 18 & 10 & 8 & \\
\hline Rx & 1 & 1 & 0 & \\
\hline Seminal vesicle invasion & & & & 0.018 \\
\hline Negative & 62 & 24 & 38 & \\
\hline Positive & 8 & 7 & 1 & \\
\hline
\end{tabular}

$m i R-141$ and $m i R-146 b-3 p$ assays exhibited any detectable crossreactivity, but relative detection of the non-specific miRNA was 45 orders of magnitude less than the specific miRNA (Figure 3B). Collectively, these results indicated that quantitation of circulating miR-141, miR-146b-3p, miR-194 and miR-375 using a multiplexed Taqman assay was a robust approach.

Kaplan-Meier (KM) analysis was used to test for an association between the circulating miRNAs and BCR. For each miRNA, patients were dichotomised into two groups based on median levels. Higher circulating levels of $m i R-146 b-3 p$ and $m i R-194$ were associated with an increased risk of BCR but $m i R-141$ and $m i R-375$ were not (Figure 4). The prognostic capacity of the circulating miRNAs was further assessed using Cox proportional hazard regression. Univariate analysis demonstrated that high circulating levels of $m i R-146 b-3 p$ were associated with a reduced recurrencefree interval, as was pre-operative serum PSA concentration, Gleason grade and seminal vesicle invasion (SVI) (Table 3). A combined value representing the mean normalised $\mathrm{Cq}$ of $m i R-146 b-3 p$ and $m i R-194$ possessed greater prognostic value $(P=0.004$, hazard ratio $=1.29 \quad(95 \%$ confidence interval $(\mathrm{CI})=1.07-1.57)$ ). In multivariate analysis, $m i R-146 b-3 p$, preoperative PSA and SVI were significant predictors of time to BCR (Table 3), indicating that this circulating miRNA provides prognostic information independent of standard clinicopathological parameters.

The capacity of circulating $m i R-146 b-3 p$ and $m i R-194$ to distinguish between men who subsequently recurred and men who remained disease free was further evaluated by ROC curve analysis. Circulating $m i R-146 b-3 p$ (area under the curve $(\mathrm{AUC})=0.62, P=0.095), \mathrm{miR}-194(\mathrm{AUC}=0.65, P=0.029)$, preoperative PSA $(\mathrm{AUC}=0.69, P=0.003)$ and SVI $(\mathrm{AUC}=0.60$, $P=0.013$ ) all possessed similar discriminatory power. Adding the miRNA variables to SVI significantly improved its discriminatory power $($ AUC of SVI + miRNAs $=0.75$; SVI alone $=0.60 ; P$-value of difference $=0.007$ ), whereas the AUC of PSA combined with the
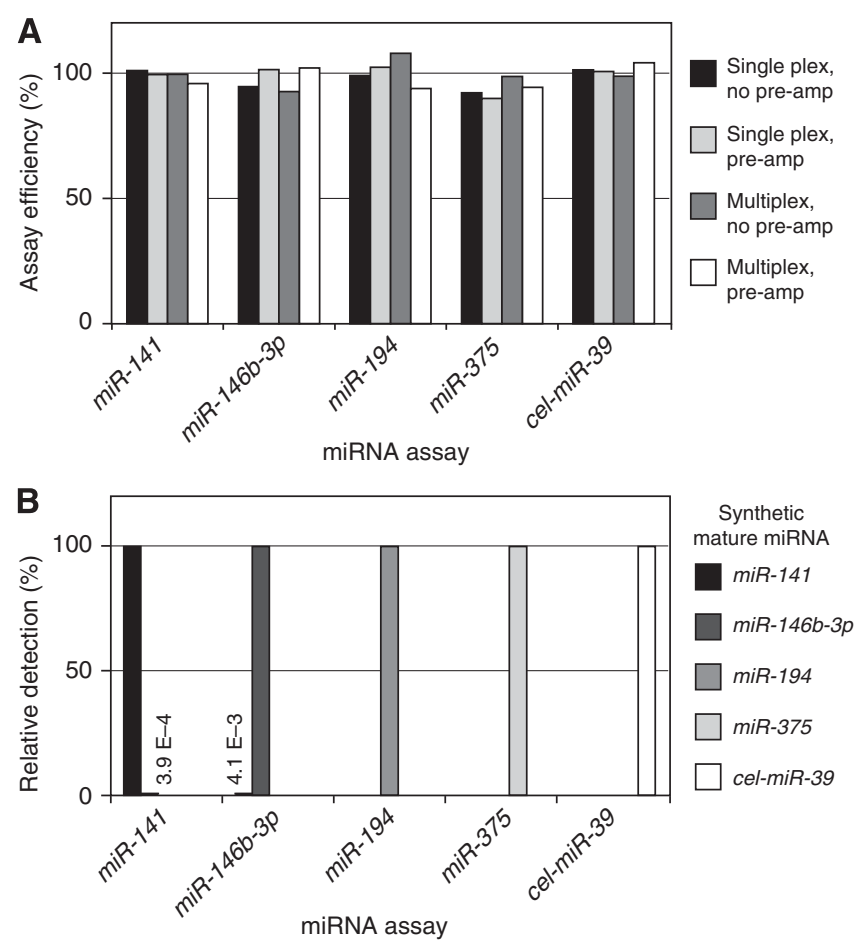

Figure 3. Efficiency and specificity of Taqman miRNA assays. (A) PCR efficiencies for each assay in either single plex or multiplexed reactions, with and without pre-amplification. (B) Specificity of the miRNA assays. Cross-reactivity between the assays was calculated based on the $\mathrm{Cq}$ difference between assay-specific (set to 100\%) and non-specific synthetic miRNA targets. Values for the two cases of detectable crossreactivity are shown on the graph.

miRNAs was only marginally increased compared with PSA alone $(\mathrm{PSA}+$ miRNAs $=0.74 ;$ PSA alone $=0.69 ; P=0.297)($ Figure 5$)$.

We also evaluated the correlation between circulating miRNAs and clinicopathological factors (Table 4). Neither $m i R-146 b$-3p nor $m i R-194$ was associated with primary Gleason grade, pathologic stage or SVI. Increased $m i R-194$ was positively correlated with age, but $m i R-146 b-3 p$ was not. Interestingly, $m i R-146 b-3 p$ was negatively correlated with margin status. Both miRNAs showed a trend towards positive correlation with pre-operative serum PSA levels, but this did not reach statistical significance.

Expression of circulating miRNAs in prostate cancer. Given their association with outcome, we hypothesised that circulating $m i R-146 b-3 p$ and $m i R-194$ were derived from cancer cells. As a preliminary effort to test this hypothesis, the expression of these miRNAs was evaluated in tumour samples. Two clinical cohorts were evaluated, one from Memorial Sloan-Kettering Cancer Center (MSKCC cohort) and the other from the Erasmus Medical Center (Erasmus cohort). In both of the cohorts, $m i R-146 b-3 p$ expression in normal and malignant tissues was very low (not detectable in 38 out of 99 (Erasmus) and 80 out of 141 (MSKCC) samples), precluding further analysis. By contrast, miR-194 was robustly expressed in normal and malignant prostate cells and was found to be significantly higher in both lymph-node metastases (Erasmus) and a mixed population of metastases (MSKCC) (Figure 6A). Kaplan-Meier survival analysis revealed that high miR-194 was a poor prognostic indicator in the Erasmus cohort, but this association did not reach statistical significance (Figure 6B, left). When the MSKCC cohort was dichotomised by the median miR-194 expression, no association with BCR was observed (data not shown). However, the highest quartile of miR-194 in the MSKCC cohort had a significantly poorer prognosis than the lower quartile 

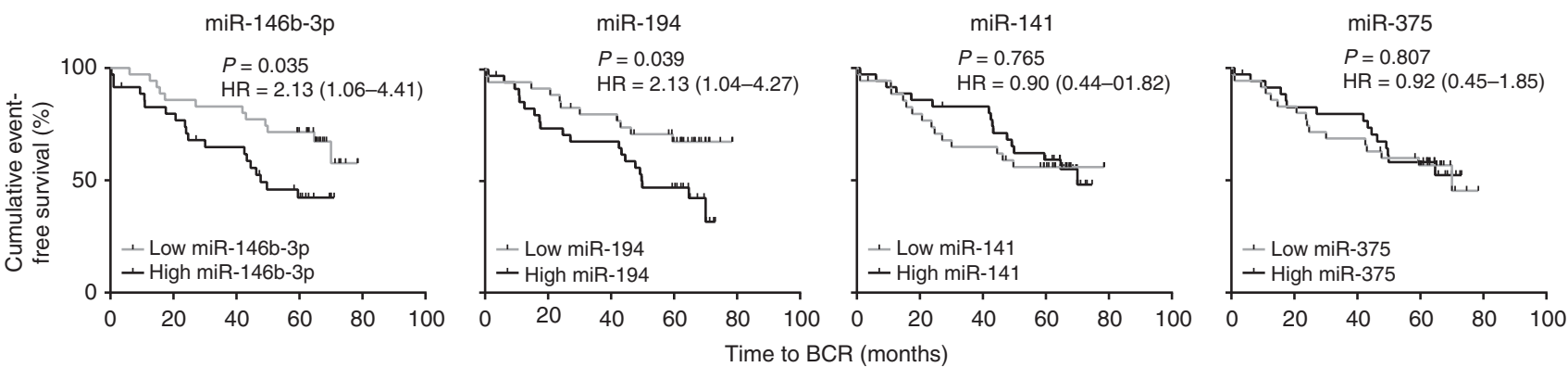

Figure 4. Kaplan-Meier analysis in the validation set $(n=70)$ showing estimated biochemical recurrence (BCR)-free probability in patients with high (above median) or low (below median) levels of circulating miRNAs. Curves were compared using a log-rank test. $P$-values and hazard ratios (HRs; 95\% confidence interval in parentheses) are shown.

\begin{tabular}{|c|c|c|c|c|c|c|}
\hline \multirow[b]{3}{*}{ Variable $^{a}$} & & & \multicolumn{4}{|c|}{ Multivariate } \\
\hline & \multicolumn{2}{|c|}{ Univariate } & \multicolumn{2}{|c|}{ Inclusion } & \multicolumn{2}{|c|}{ Stepwise $^{c}$} \\
\hline & $\mathrm{HR}(95 \% \mathrm{Cl})^{\mathrm{b}}$ & $P$-value & $\mathrm{HR}(95 \% \mathrm{Cl})$ & $P$-value & $\mathrm{HR}(95 \% \mathrm{Cl})$ & $P$-value \\
\hline miR-141 & $0.97(0.75-1.26)$ & 0.829 & $0.91(0.68-1.21)$ & 0.520 & & \\
\hline miR-146b-3p & $1.13(1.01-1.26)$ & 0.020 & $1.16(1.03-1.31)$ & 0.017 & $1.14(1.02-1.27)$ & 0.019 \\
\hline miR-194 & $1.13(0.97-1.31)$ & 0.112 & $1.08(0.91-1.28)$ & 0.399 & & \\
\hline miR-375 & $0.88(0.55-1.43)$ & 0.613 & $0.83(0.46-1.49)$ & 0.526 & & \\
\hline Pre-operative PSA & $1.14(1.06-1.24)$ & 0.001 & $1.10(1.00-1.20)$ & 0.045 & $1.11(1.02-1.20)$ & 0.013 \\
\hline Gleason score $(3+4$ vs $4+3)$ & $2.29(1.11-4.71)$ & 0.023 & $1.56(0.60-4.10)$ & 0.366 & & \\
\hline Pathologic stage (pT2 vs pT3) & $1.86(0.90-3.88)$ & 0.090 & $1.43(0.53-3.85)$ & 0.481 & & \\
\hline Surgical margins (R0 vs R1) & $1.45(0.68-3.09)$ & 0.352 & $1.00(0.34-2.95)$ & 0.998 & & \\
\hline SVI (negative vs positive) & $3.86(1.64-9.05)$ & 0.007 & $2.59(0.91-7.41)$ & 0.077 & $3.50(1.47-8.29)$ & 0.005 \\
\hline
\end{tabular}
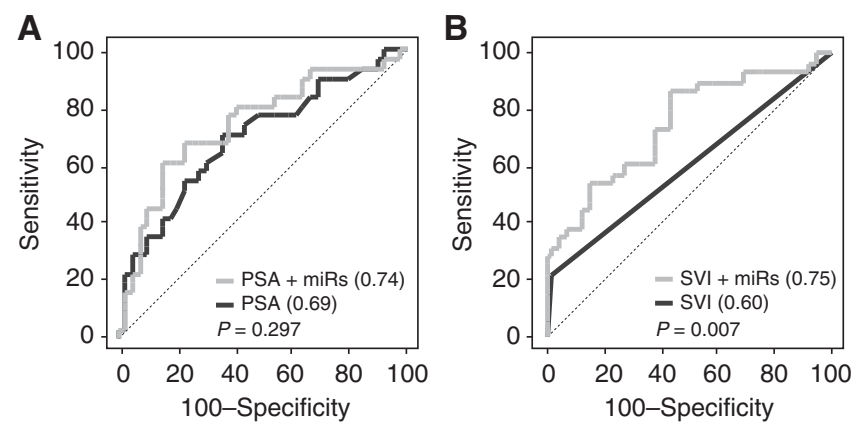

Figure 5. ROC curve analysis in the validation set $(n=70)$ comparing the ability of clinical parameters alone or in combination with circulating miRNAs to identify men who experience biochemical recurrence. (A) Comparison of pre-operative PSA alone (dark grey) or combined with circulating miR-146b-3p and miR-194 (light grey).

(B) Comparison of seminal vesicle invasion (SVI) alone (dark grey) or combined with circulating miR-146b-3p and miR-194 (light grey). Area under the curve (AUC) is shown in brackets. The Delong method was used to compare the AUCs; P-values are shown.
(Figure 6B, right). Univariate Cox proportional hazard regression revealed that high $m i R-194$ was significantly correlated with time to BCR in the MSKCC cohort $(P=0.033$, hazard ratio $=3.33(95 \%$ $\mathrm{CI}=1.12-9.87))$ and with time to metastasis in the Erasmus cohort $(P=0.026$, hazard ratio $=3.75(95 \% \mathrm{CI}=1.28-10.97))$.

\section{DISCUSSION}

Biomarkers that provide accurate prognostic information for men with prostate cancer are urgently required. Here, we demonstrate for the first time that circulating $m i R-146 b-3 p$ and $m i R-194$, measured immediately before RP, can be used to predict disease progression in patients of intermediate risk. This finding was achieved by employing a set of samples with comprehensive longterm clinical outcome data. In addition, circulating miR-146b-3p and miR-194 were only weakly correlated with other clinical variables, suggesting that they provide new prognostic information. Therefore, these markers have the potential to improve the management of intermediate risk localised prostate cancers, which would be of significant clinical utility. 


\begin{tabular}{|c|c|c|c|c|}
\hline Variable & $\operatorname{miR}-146 b-3 p^{a}$ & $\boldsymbol{P}$-value ${ }^{\mathrm{b}}$ & $\operatorname{miR}-194^{a}$ & $P$-value ${ }^{b}$ \\
\hline \multicolumn{5}{|l|}{ Age, years } \\
\hline $\begin{array}{l}<65(n=40) \\
\geqslant 65(n=30)\end{array}$ & $\begin{array}{l}-7.98 \\
-8.84\end{array}$ & 0.143 & $\begin{array}{l}3.77 \\
5.32\end{array}$ & 0.004 \\
\hline \multicolumn{5}{|c|}{ Pre-operative PSA $\left(\mathrm{ng} \mathrm{ml}^{-1}\right.$ ) } \\
\hline $\begin{array}{l}<10(n=53) \\
\geqslant 10(n=17)\end{array}$ & $\begin{array}{l}-8.77 \\
-7.03\end{array}$ & 0.095 & $\begin{array}{l}4.30 \\
5.18\end{array}$ & 0.073 \\
\hline \multicolumn{5}{|l|}{ Gleason score } \\
\hline $\begin{array}{l}3+4(n=37) \\
4+3(n=33)\end{array}$ & $\begin{array}{l}-8.65 \\
-8.11\end{array}$ & 0.923 & $\begin{array}{l}4.35 \\
4.90\end{array}$ & 0.285 \\
\hline \multicolumn{5}{|c|}{ Pathologic stage } \\
\hline $\begin{array}{l}\text { pT2 }(n=33) \\
\text { pT3/pT4 }(n=37)\end{array}$ & $\begin{array}{l}-7.96 \\
-8.77\end{array}$ & 0.411 & $\begin{array}{l}4.88 \\
4.58\end{array}$ & 0.671 \\
\hline \multicolumn{5}{|c|}{ Surgical margins } \\
\hline $\begin{array}{l}\text { R0 }(n=51) \\
\text { R1 }(n=18)\end{array}$ & $\begin{array}{l}-7.96 \\
-9.97\end{array}$ & 0.014 & $\begin{array}{l}4.58 \\
5.49\end{array}$ & 0.389 \\
\hline \multicolumn{5}{|c|}{ Seminal vesicle invasion } \\
\hline $\begin{array}{l}\text { Negative }(n=62) \\
\text { Positive }(n=8)\end{array}$ & $\begin{array}{l}-8.57 \\
-7.55 \\
\end{array}$ & 0.419 & $\begin{array}{l}4.76 \\
5.08 \\
\end{array}$ & 0.906 \\
\hline $\begin{array}{l}\text { Abbreviation: PSA }=p \\
{ }^{a_{M}} \text { Median normalised } C \\
b_{\text {Mann-Whitney test. }}\end{array}$ & state-specific antigen. & & & \\
\hline
\end{tabular}

While $m i R-146 b-3 p$ has not been directly linked to prostate cancer, there is accumulating evidence for a role of the miR-146 family in this malignancy. In an early miRNA profiling study, miR-146a-5p was shown to be commonly overexpressed in solid tumours, including prostate cancer (Volinia et al, 2006). More recently, it was reported that the expression of both miR-146a-5p and $m i R-146 b-5 p$ was reduced in a cell line model of castrationresistant prostate cancer compared with androgen-dependent prostate cancer cells (Lin et al, 2008) and miR-146b-5p was decreased in metastatic vs non-metastatic xenografts (Watahiki et $a l, 2011)$. How the loss of $m i R-146$ during prostate cancer progression fits with our observation that serum $m i R-146 b-3 p$ is a marker of disease recurrence is currently unclear. Interestingly, the $5 \mathrm{p}$ and $3 \mathrm{p}$ forms of $m i R-146 b$ have converse associations with recurrence of non-small cell lung cancer (Patnaik et al, 2009, 2011), providing a precedent for distinct functions of the $m i R-146 b$ pairs in cancer progression. Despite its association with disease behaviour, $m i R-146 b-3 p$ does not appear to be expressed at high levels in normal or malignant prostate tissue. We envision at least three explanations for this apparent discrepancy. First, $m i R-146 b-3 p$ could be efficiently released from cancer cells into circulation such that it does not accumulate in the tumour. Preferential cellular export of certain miRNAs has been reported previously (for review, see Selth et al, 2012). Indeed, $m i R-1$ and $m i R-133 a$ are increased in serum in response to acute myocardial infarction but the levels of both are reduced in the infarcted myocardial tissue (Kuwabara et al, 2011), indicating that large discrepancies between the levels of miRNA in circulation compared with their tissue of origin are possible. Second, serum $m i R-146 b-3 p$ may originate from circulating tumour cells (CTCs) and/or micrometastases that
A
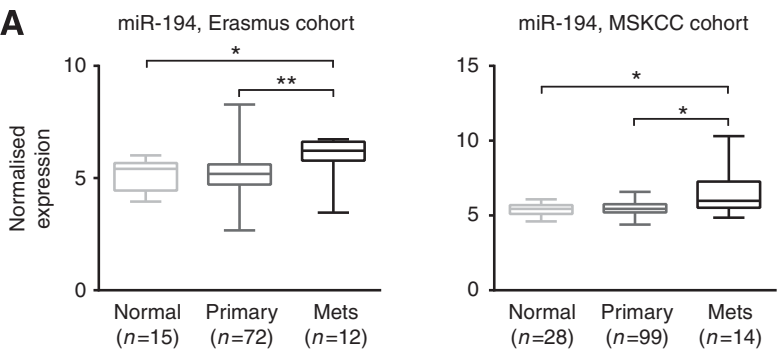

B

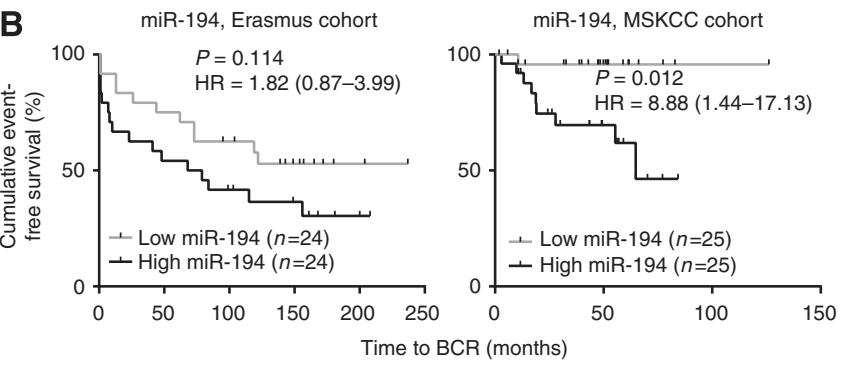

Figure 6. Expression and prognostic value of miR-194 in prostate tumours. (A) Relative expression of miR-194 in normal prostate tissue, primary prostate tumours (Primary) and metastases (Met). Two different cohorts, Erasmus and MSKCC were analysed. LN, lymph nodes. Statistically significant differences were assessed using a Kruskal-Wallis one-way ANOVA $\left({ }^{\star} P<0.05 ;{ }^{* *} P<0.01\right)$. (B) KaplanMeier curves showing estimated biochemical recurrence (BCR)-free probability in patients with high (above median) or low (below median) intra-tumoural expression of miR-194 in the two cohorts. Curves were compared using a log-rank test: $P$-values and hazard ratios (HR; 95\% confidence interval in parentheses) are shown. $B C R$, biochemical relapse.

have not been detected at the time of treatment. Given its association with disease recurrence, we favour this explanation. Finally, we cannot rule out the possibility that circulating $m i R$ $146 b-3 p$ does not originate from malignant prostate cells but rather from systemic changes in response to the disease, such as inflammatory responses.

In support of our discovery that circulating miR-194 is associated with disease progression, Tong et al (2009) reported that this miRNA was elevated in tumours from men who experienced rapid BCR (within 2 years of RP) compared with men who did not experience $B C R \geqslant 10$ years after surgery. Our analysis of two large, published data sets further demonstrated that the intra-tumoural expression of $m i R-194$ was associated with poor outcome measures, including BCR and metastasis, although further analysis in larger cohorts is required to make more definitive conclusions. Collectively, these observations suggest that miR-194 may be expressed in high-risk tumours and released into circulation during carcinogenesis. Interestingly, miR-194 was recently found to be elevated in the serum of a mouse model of diffuse-type gastric cancer, suggesting that it may be a more general circulating marker of malignancy (Rotkrua et al, 2013).

Of all the circulating miRNAs previously associated with prostate cancer, $m i R-141$ and $m i R-375$ have been the most commonly identified (Mitchell et al, 2008; Brase et al, 2011; Gonzales et al, 2011; Selth et al, 2011; Bryant et al, 2012; Nguyen et al, 2012). These earlier studies demonstrated associations between $m i R-141 / m i R-375$ and clinicopathological parameters (Gleason score, pathologic stage and lymph-node status), metastatic disease and treatment response. However, while both of these 
miRNAs were elevated in men who experienced BCR in the screening cohort (note that for $m i R-375$, this was a non-significant change), neither were correlated with $\mathrm{BCR}$ in the larger validation cohort. Therefore, the potential of these circulating miRNAs as clinically useful markers for prostate cancer remains to be conclusively proven. With this in mind, it is worth noting that studies of circulating miRNAs to date are highlighted by conflicting data and outcomes, which likely arise from heterogeneity in terms of objectives and methodology. Improving the consistency and standardisation of these factors is of critical importance for future work.

A role in epithelial-mesenchymal plasticity is an emerging link between many of the circulating miRNAs associated with prostate cancer. MiR-141 and miR-200b are members of the miR-200 family, which target the Zeb1/2 transcription factors and thereby repress epithelial-mesenchymal transition (EMT) (Bracken et al, 2009). MiR-429 is another miR-200 family member that was significantly elevated in the BCR group of our screening cohort, although it was filtered from further analysis because of low expression (average $\mathrm{Cq}=41.3$ in the screening samples). $M i R-194$ can also inhibit EMT in models of liver (Meng et al, 2010) and endometrial cancer (Dong et al, 2011) and may directly target the mesenchymal factor $\mathrm{N}$-cadherin (Song et al, 2011). Additionally, a recent study found that $m i R-375$ could partially reverse EMT in MCF-7 breast cancer cells (Ward et al, 2012). It is currently unclear why these 'epithelial' miRNAs are elevated in the circulation of men with metastatic prostate cancer (i.e., $m i R-141, m i R-200 b$ and miR-375; Mitchell et al, 2008; Brase et al, 2011; Selth et al, 2011; Bryant et al, 2012) or localised prostate cancer with a poor prognosis ( $m i R-194$, this study). One possibility is that they are indicative of CTCs and/or metastases that have undergone or are undergoing a mesenchymal-epithelial transition (MET), a process likely to be important for efficient metastatic colonisation (Gao et al, 2012). Supporting this concept, Madhavan et al (2012) recently demonstrated that circulating $m i R-200$ family members and $m i R-375$ are surrogate markers for CTCs in breast cancer and correlated with disease progression and overall survival. The circulating levels of miR-200 family members have also been associated with a poor outcome in gastric and endometrial cancer (Valladares-Ayerbes et al, 2012; Torres et al, 2013). Collectively, these findings suggest that disruption of MET to prevent metastatic colonisation may be an effective therapeutic strategy.

Even with a pre-amplification step, some serum prostate cancerassociated miRNAs reported previously and in this study (e.g., $m i R-141$ and $m i R-146 b-3 p)$ are at the limit of detection by Taqman qRT-PCR. Moreover, others that are potentially useful markers of BCR (e.g., miR-429) were discarded from our analyses because of low concentration. We believe that emerging technologies, such as NanoString, digital PCR and miRNA-specific nanopores (Wang et al, 2011), will increase the accuracy of miRNA detection from cell-free fractions of body fluids and thereby enhance the utility of these molecules as disease-specific markers.

A limitation of this study is the validation cohort, which was small, limited to Gleason score 7 patients, and enriched for men who experienced early biochemical disease progression. Moreover, although BCR has become the de facto measure of the effectiveness of RP (Nielsen and Partin, 2007), it does not always translate into clinical progression. Indeed, there have been conflicting reports regarding the utility of $\mathrm{BCR}$ as a predictor of metastasis and cancer-specific survival (Agarwal et al, 2008; Boorjian et al, 2011). As such, the results should be interpreted with caution and with the caveat that additional studies might uncover circulating miRNAs that add to or outperform the markers identified here, particularly in relation to prognosing systemic progression and/or prostate cancer death.

Despite these limitations, it is worth reinforcing the potential utility of circulating miRNAs such as $m i R-146 b-3 p$ and $m i R-194$ that may assist in prognosis of intermediate risk patients, a group that engenders considerable clinical uncertainty. We intend to validate our findings in a larger, prospectively collected cohort of such patients and assess whether these miRNAs add to preoperative nomograms and thereby have the potential to reduce rates of overtreatment. In this respect, it is important to note that whereas pre-operative clinical parameters, such as Gleason score, can be affected by undersampling (Haas et al, 2007) and/or molecular heterogeneity of multifocal disease (Barry et al, 2007), circulating miRNAs are likely to provide an overall snapshot of changes occurring in response to tumour growth. Moreover, circulating miRNAs can be measured non-invasively and repeatedly, which may assist in treatment decision-making. We also believe that circulating miRNAs are likely to have potential as prognostic markers in men treated by active surveillance or in men with high-risk localised cancers, two further applications that will be assessed in future work.

\section{ACKNOWLEDGEMENTS}

We thank the study participants, urologists, nurses, histopathologists, who assisted in the recruitment and collection of patient material and information. In particular, the authors are grateful to Ms Pamela Saunders, Ms Katerina Mitsakos and Ms Anne-Maree Haynes, who facilitated the identification and retrieval of suitable clinical samples. The Australian Prostate Cancer BioResource is supported by the National Health and Medical Research Council of Australia (enabling grants 290456 and 614296) and the Prostate Cancer Foundation of Australia (PCFA). The Adelaide Prostate Cancer Research Centre is supported by an establishment grant from the PCFA (ID 2011/0452). This work was supported by Young Investigator Awards from the Prostate Cancer Foundation (the Foundation 14 award; LAS) and the PCFA (LAS, YI 0810) and a grant from the PCFA/Cancer Australia (ID 1012337 to LMB and WDT). LMB holds a senior research fellowship from the Cancer Council of South Australia. Finally, we would like to acknowledge the late Prof Robert Sutherland, who was one of the founders of the APCB.

\section{CONFLICT OF INTEREST}

The authors declare no conflict of interest.

\section{REFERENCES}

Agarwal PK, Sadetsky N, Konety BR, Resnick MI, Carroll PR. Cancer of the Prostate Strategic Urological Research E (2008) Treatment failure after primary and salvage therapy for prostate cancer: likelihood, patterns of care, and outcomes. Cancer 112(2): 307-314.

Andriole GL, Crawford ED, Grubb 3rd RL, Buys SS, Chia D, Church TR, Fouad MN, Gelmann EP, Kvale PA, Reding DJ, Weissfeld JL, Yokochi LA, O'Brien B, Clapp JD, Rathmell JM, Riley TL, Hayes RB, Kramer BS, Izmirlian G, Miller AB, Pinsky PF, Prorok PC, Gohagan JK, Berg CD (2009) Mortality results from a randomized prostate-cancer screening trial. N Engl J Med 360(13): 1310-1319.

Barry M, Perner S, Demichelis F, Rubin MA (2007) TMPRSS2-ERG fusion heterogeneity in multifocal prostate cancer: clinical and biologic implications. Urology 70(4): 630-633.

Boorjian SA, Thompson RH, Tollefson MK, Rangel LJ, Bergstralh EJ, Blute ML, Karnes RJ (2011) Long-term risk of clinical progression after biochemical recurrence following radical prostatectomy: the impact of time from surgery to recurrence. Eur Urol 59(6): 893-899.

Bracken CP, Gregory PA, Khew-Goodall Y, Goodall GJ (2009) The role of microRNAs in metastasis and epithelial-mesenchymal transition. Cell Mol Life Sci 66(10): 1682-1699. 
Brase JC, Johannes M, Schlomm T, Falth M, Haese A, Steuber T, Beissbarth T, Kuner R, Sultmann H (2011) Circulating miRNAs are correlated with tumor progression in prostate cancer. Int J Cancer 128(3): 608-616.

Bryant RJ, Pawlowski T, Catto JW, Marsden G, Vessella RL, Rhees B, Kuslich C, Visakorpi T, Hamdy FC (2012) Changes in circulating microRNA levels associated with prostate cancer. Br J Cancer 106(4): 768-774.

Bushati N, Cohen SM (2007) microRNA functions. Annu Rev Cell Dev Biol 23: 175-205.

Chou R, Croswell JM, Dana T, Bougatsos C, Blazina I, Fu R, Gleitsmann K, Koenig HC, Lam C, Maltz A, Rugge JB, Lin K (2011) Screening for prostate cancer: a review of the evidence for the U.S. Preventive Services Task Force. Ann Intern Med 155(11): 762-771.

Croce CM (2009) Causes and consequences of microRNA dysregulation in cancer. Nat Rev Genet 10(10): 704-714.

D’Amico AV, Whittington R, Malkowicz SB, Schultz D, Blank K, Broderick GA, Tomaszewski JE, Renshaw AA, Kaplan I, Beard CJ, Wein A (1998) Biochemical outcome after radical prostatectomy, external beam radiation therapy, or interstitial radiation therapy for clinically localized prostate cancer. JAMA 280(11): 969-974.

Deo A, Carlsson J, Lindlof A (2011) How to choose a normalization strategy for miRNA quantitative real-time (qPCR) arrays. J Bioinform Comput Biol 9(6): 795-812.

Dong P, Kaneuchi M, Watari H, Hamada J, Sudo S, Ju J, Sakuragi N (2011) MicroRNA-194 inhibits epithelial to mesenchymal transition of endometrial cancer cells by targeting oncogene BMI-1. Mol Cancer 10: 99 .

Friedman RC, Farh KK, Burge CB, Bartel DP (2009) Most mammalian mRNAs are conserved targets of microRNAs. Genome Res 19(1): 92-105.

Gao D, Vahdat LT, Wong S, Chang JC, Mittal V (2012) Microenvironmental regulation of epithelial-mesenchymal transitions in cancer. Cancer Res 72(19): 4883-4889.

Gonzales JC, Fink LM, Goodman Jr. OB, Symanowski JT, Vogelzang NJ, Ward DC (2011) Comparison of circulating MicroRNA 141 to circulating tumor cells, lactate dehydrogenase, and prostate-specific antigen for determining treatment response in patients with metastatic prostate cancer. Clin Genitourin Cancer 9(1): 39-45.

Haas GP, Delongchamps NB, Jones RF, Chandan V, Serio AM, Vickers AJ, Jumbelic M, Threatte G, Korets R, Lilja H, de la Roza G (2007) Needle biopsies on autopsy prostates: sensitivity of cancer detection based on true prevalence. J Natl Cancer Inst 99(19): 1484-1489.

Jemal A, Bray F, Center MM, Ferlay J, Ward E, Forman D (2011) Global cancer statistics. CA Cancer J Clin 61(2): 69-90.

Kelly BD, Miller N, Healy NA, Walsh K, Kerin MJ (2012) A review of expression profiling of circulating microRNAs in men with prostate cancer. BJU Int 111(1): 17-21.

Kirschner MB, Kao SC, Edelman JJ, Armstrong NJ, Vallely MP, van Zandwijk N, Reid G (2011) Haemolysis during sample preparation alters microRNA content of plasma. PLoS ONE 6(9): e24145.

Kroh EM, Parkin RK, Mitchell PS, Tewari M (2010) Analysis of circulating microRNA biomarkers in plasma and serum using quantitative reverse transcription-PCR (qRT-PCR). Methods 50(4): 298-301.

Kuwabara Y, Ono K, Horie T, Nishi H, Nagao K, Kinoshita M, Watanabe S, Baba O, Kojima Y, Shizuta S, Imai M, Tamura T, Kita T, Kimura T (2011) Increased microRNA-1 and microRNA-133a levels in serum of patients with cardiovascular disease indicate the existence of myocardial damage. Circ Cardiovasc Genet 4(4): 446-454.

Lawrie CH, Gal S, Dunlop HM, Pushkaran B, Liggins AP, Pulford K, Banham AH, Pezzella F, Boultwood J, Wainscoat JS, Hatton CS, Harris AL (2008) Detection of elevated levels of tumour-associated microRNAs in serum of patients with diffuse large B-cell lymphoma. $\mathrm{Br} J$ Haematol 141(5): 672-675.

Lin SL, Chiang A, Chang D, Ying SY (2008) Loss of mir-146a function in hormone-refractory prostate cancer. RNA 14(3): 417-424.

Lopez-Romero P (2011) Pre-processing and differential expression analysis of Agilent microRNA arrays using the AgiMicroRna Bioconductor library. BMC Genomics 12: 64 .

Madhavan D, Zucknick M, Wallwiener M, Cuk K, Modugno C, Scharpff M, Schott S, Heil J, Turchinovich A, Yang R, Benner A, Riethdorf S, Trumpp A, Sohn C, Pantel K, Schneeweiss A, Burwinkel B (2012) Circulating miRNAs as surrogate markers for circulating tumor cells and prognostic markers in metastatic breast cancer. Clin Cancer Res 18(21): 5972-5982.
Martens-Uzunova ES, Jalava SE, Dits NF, van Leenders GJ, Moller S, Trapman J, Bangma CH, Litman T, Visakorpi T, Jenster G (2011) Diagnostic and prognostic signatures from the small non-coding RNA transcriptome in prostate cancer. Oncogene 31(8): 978-991.

Meng Z, Fu X, Chen X, Zeng S, Tian Y, Jove R, Xu R, Huang W (2010) miR-194 is a marker of hepatic epithelial cells and suppresses metastasis of liver cancer cells in mice. Hepatology 52(6): 2148-2157.

Mestdagh P, Van Vlierberghe P, De Weer A, Muth D, Westermann F, Speleman F, Vandesompele J (2009) A novel and universal method for microRNA RT-qPCR data normalization. Genome Biol 10(6): R64.

Mitchell PS, Parkin RK, Kroh EM, Fritz BR, Wyman SK, PogosovaAgadjanyan EL, Peterson A, Noteboom J, O'Briant KC, Allen A, Lin DW, Urban N, Drescher CW, Knudsen BS, Stirewalt DL, Gentleman R, Vessella RL, Nelson PS, Martin DB, Tewari M (2008) Circulating microRNAs as stable blood-based markers for cancer detection. Proc Natl Acad Sci USA 105(30): 10513-10518.

Nguyen HC, Xie W, Yang M, Hsieh CL, Drouin S, Lee GS, Kantoff PW (2012) Expression differences of circulating microRNAs in metastatic castration resistant prostate cancer and low-risk, localized prostate cancer. Prostate 73(4): 346-354.

Nielsen ME, Partin AW (2007) The impact of definitions of failure on the interpretation of biochemical recurrence following treatment of clinically localized prostate cancer. Rev Urol 9(2): 57-62.

Patnaik SK, Kannisto E, Knudsen S, Yendamuri S (2009) Evaluation of microRNA expression profiles that may predict recurrence of localized stage I non-small cell lung cancer after surgical resection. Cancer Res 70(1): 36-45.

Patnaik SK, Kannisto E, Mallick R, Yendamuri S (2011) Overexpression of the lung cancer-prognostic miR-146b microRNAs has a minimal and negative effect on the malignant phenotype of A549 lung cancer cells. PLoS ONE 6(7): e22379.

Pritchard CC, Kroh E, Wood B, Arroyo JD, Dougherty KJ, Miyaji MM, Tait JF, Tewari M (2012) Blood cell origin of circulating microRNAs: a cautionary note for cancer biomarker studies. Cancer Prev Res (Phila) 5(3): 492-497.

Rotkrua P, Shimada S, Mogushi K, Akiyama Y, Tanaka H, Yuasa Y (2013) Circulating microRNAs as biomarkers for early detection of diffuse-type gastric cancer using a mouse model. Br J Cancer 108(4): 932-940.

Schroder FH, Hugosson J, Roobol MJ, Tammela TL, Ciatto S, Nelen V, Kwiatkowski M, Lujan M, Lilja H, Zappa M, Denis LJ, Recker F, Berenguer A, Maattanen L, Bangma CH, Aus G, Villers A, Rebillard X, van der Kwast T, Blijenberg BG, Moss SM, de Koning HJ, Auvinen A (2009) Screening and prostate-cancer mortality in a randomized European study. N Engl J Med 360(13): 1320-1328.

Selth LA, Tilley WD, Butler LM (2012) Circulating microRNAs: macro-utility as markers of prostate cancer? Endocr Relat Cancer 19(4): R99-R113.

Selth LA, Townley S, Gillis JL, Ochnik AM, Murti K, Macfarlane RJ, Chi KN, Marshall VR, Tilley WD, Butler LM (2011) Discovery of circulating microRNAs associated with human prostate cancer using a mouse model of disease. Int J Cancer 131(3): 652-661.

Song Y, Zhao F, Wang Z, Liu Z, Chiang Y, Xu Y, Gao P, Xu H (2011) Inverse association between miR-194 expression and tumor invasion in gastric cancer. Ann Surg Oncol 19(Suppl 3): S509-S517.

Taylor BS, Schultz N, Hieronymus H, Gopalan A, Xiao Y, Carver BS, Arora VK, Kaushik P, Cerami E, Reva B, Antipin Y, Mitsiades N, Landers T, Dolgalev I, Major JE, Wilson M, Socci ND, Lash AE, Heguy A, Eastham JA, Scher HI, Reuter VE, Scardino PT, Sander C, Sawyers CL, Gerald WL (2010) Integrative genomic profiling of human prostate cancer. Cancer Cell 18(1): 11-22.

Tong AW, Fulgham P, Jay C, Chen P, Khalil I, Liu S, Senzer N, Eklund AC, Han J, Nemunaitis J (2009) MicroRNA profile analysis of human prostate cancers. Cancer Gene Ther 16(3): 206-216.

Torres A, Torres K, Pesci A, Ceccaroni M, Paszkowski T, Cassandrini P, Zamboni G, Maciejewski R (2013) Diagnostic and prognostic significance of miRNA signatures in tissues and plasma of endometrioid endometrial carcinoma patients. Int J Cancer 132(7): 1633-1645.

Valladares-Ayerbes M, Reboredo M, Medina-Villaamil V, Iglesias-Diaz P, Lorenzo-Patino MJ, Haz M, Santamarina I, Blanco M, Fernandez-Tajes J, Quindos M, Carral A, Figueroa A, Anton-Aparicio LM, Calvo L (2012) Circulating miR-200c as a diagnostic and prognostic biomarker for gastric cancer. J Transl Med 10: 186. 
Volinia S, Calin GA, Liu CG, Ambs S, Cimmino A, Petrocca F, Visone R, Iorio M, Roldo C, Ferracin M, Prueitt RL, Yanaihara N, Lanza G, Scarpa A, Vecchione A, Negrini M, Harris CC, Croce CM (2006) A microRNA expression signature of human solid tumors defines cancer gene targets. Proc Natl Acad Sci USA 103(7): 2257-2261.

Wang Y, Zheng D, Tan Q, Wang MX, Gu LQ (2011) Nanopore-based detection of circulating microRNAs in lung cancer patients. Nat Nanotechnol 6(10): 668-674.

Ward A, Balwierz A, Zhang JD, Kublbeck M, Pawitan Y, Hielscher T, Wiemann S, Sahin O (2012) Re-expression of microRNA-375 reverses both tamoxifen resistance and accompanying EMT-like properties in breast cancer. Oncogene 32(9): 1173-1182.
Watahiki A, Wang Y, Morris J, Dennis K, O’Dwyer HM, Gleave M, Gout PW (2011) MicroRNAs associated with metastatic prostate cancer. PLoS ONE 6(9): e24950.

Weiland M, Gao XH, Zhou L, Mi QS (2012) Small RNAs have a large impact: circulating microRNAs as biomarkers for human diseases. RNA Biol 9(6): $850-859$.

This work is published under the standard license to publish agreement. After 12 months the work will become freely available and the license terms will switch to a Creative Commons AttributionNonCommercial-Share Alike 3.0 Unported License. 